OPEN ACCESS

Edited by: Yadir Torres,

Sevilla University, Spain

Reviewed by:

Débora Coraça-Huber,

Innsbruck Medical University, Austria

Lia Rimondini,

University of Eastern Piedmont, Italy

${ }^{*}$ Correspondence:

Aldo R. Boccaccini aldo.boccaccini@ww.uni-erlangen.de

Specialty section: This article was submitted to Biomaterials,

a section of the journal

Frontiers in Materials

Received: 27 September 2020 Accepted: 25 November 2020

Published: 14 January 2021

Citation:

Arango-Ospina M, Lasch $K$, Weidinger $J$ and Boccaccini AR (2021) Manuka Honey and Zein Coatings Impart Bioactive Glass Bone Tissue Scaffolds Antibacterial Properties and

Superior Mechanical Properties.

Front. Mater. 7:610889

doi: $10.3389 /$ fmats.2020.610889

\section{Manuka Honey and Zein Coatings Impart Bioactive Glass Bone Tissue Scaffolds Antibacterial Properties and Superior Mechanical Properties}

\author{
Marcela Arango-Ospina, Kristina Lasch, Julius Weidinger and Aldo R. Boccaccini * \\ Department of Materials Science and Engineering, Institute of Biomaterials, University of Erlangen-Nuremberg, Erlangen, \\ Germany
}

The combination of traditional herbal medicine (phytotherapeutic agents) with bioactive glasses is a promising strategy to generate advanced scaffolds for bone tissue engineering (BTE). An old remedy used for wound care since ancient times is honey. The antioxidant, antimicrobial and antibacterial properties of Manuka honey, in particular, make it an attractive substance for application in BTE scaffolds to prevent infections and biofilm formation. In this study 45S5 bioactive glass-based scaffolds produced via the foam replica technique were coated with corn protein zein and Manuka honey with two purposes: to improve the mechanical properties of the brittle scaffolds and to impart antibacterial properties. The morphology and chemical composition of the coated scaffolds were characterized with scanning electron microscopy and Fourier transform infrared spectroscopy, respectively, demonstrating the presence of Manuka honey in the coating. The release of the honey was quantified via ultraviolet-visible spectrophotometry; moreover, the antibacterial activity against Staphylococcus aureus was evaluated via colony-forming units counting, reduction of Alamar blue and turbidity measurements. Our findings suggest the effective combination of Manuka honey and bioactive glass, adding one more system to the novel family of bioactive glass scaffolds functionalized with phytotherapeutic agents.

Keywords: bioactive glass (45S5), manuka honey, zein, polymer coating, antibacterial activity

\section{INTRODUCTION}

One of the first approaches of humanity to heal wounds, tackle inflammation or other sources of pain was the use of natural remedies, more exactly herbal ingredients (Thakur et al., 2011). A wide range of knowledge on the healing effects of plants has been passed down through generations. Although today's medical research is gaining renewed and increasing interest in the field of herbal medicine, the mechanisms of action of those so-called phytotherapeutics are still not completely elucidated. The multitude of different medical agents and therefore the wide range of biological effects of phytotherapeutics are making even more complicated to truly understand the detailed mechanism of healing (Schuhladen et al., 2019). However, research in the biomaterials field is increasing to exploit the advantages and the potential of herbal medicine, usually combining herbal or plant extracts with engineered biomaterials (Wang et al., 2018; Banerjee and Bose, 2019). 
An interesting group of natural compounds under research are honeys. Honeys gain their antimicrobial properties to a large extent through conversion of ingredients in the pollen of the plant. Because of their antibacterial effect and ability to keep wounds moist and clean, to prevent them from becoming infected, honey has been used for wound care since ancient times (Mandal and Mandal, 2011). One specific type of honey, the Manuka honey $(\mathrm{MH})$, is specifically interesting due to its wide range of antibacterial and anti-inflammatory effects (Speer et al., 2015; Almasaudi et al., 2016). The antibacterial effect makes this honey a promising natural remedy to prevent bacterial infection not only in wound care, but also on medical implants and in scaffolds for tissue regeneration. Infection is a major issue in orthopedics, since it can cause the integration of an implant to fail. Various strategies to prevent the colonization of bacteria on implant and scaffold surfaces are investigated, including coatings and incorporation of drugs for local release (Nooeaid et al., 2014; Cloutier et al., 2015; Mas-Moruno et al., 2019). The incorporation of herbal remedies like honey into medical implants and tissue scaffolds and the use of their interesting antibacterial abilities to help prevent infections, represent a promising and emerging field of research (Minden-Birkenmaier and Bowlin, 2018; Hixon et al., 2019; Schuhladen et al., 2020).

The monofloral $\mathrm{MH}$, produced by bees in New Zealand and parts of Australia, derives from the flowers of certain Leptospermum species, commonly called manuka tree (Alvarez-Suarez et al., 2014; Carter et al., 2016). The antibacterial effect of most kinds of honey is related to hydrogen peroxide, phenolic components, low $\mathrm{pH}$ and high osmotic pressure. The increased antibacterial effect of $\mathrm{MH}$ results mainly from the existence of methylglyoxal. $\mathrm{MH}$ possesses a unique Manuka factor (UMF), which represents the level of methylglyoxal in the honey and has a documented direct effect on the honey antibacterial efficiency (Alvarez-Suarez et al., 2014).

Bone tissue engineering involves the use of porous scaffolds that can act as temporary templates in bone defects and are capable of supporting the regeneration of bone tissue (Porter et al., 2009; Amini et al., 2012). A promising material for biomedical applications is bioactive glass, discovered by Hench and coworkers in the late ' $60 \mathrm{~s}$ (Hench et al., 1971). Bioactive glass (BG) of composition " $45 \mathrm{~S} 5$ " (45 wt.\% $\mathrm{SiO}_{2}, 24.5$ wt.\% $\mathrm{CaO}$, 24.5 wt. $\% \mathrm{Na}_{2} \mathrm{O}$, and 6.0 wt. $\% \mathrm{P}_{2} \mathrm{O}_{5}$ ) has been continuously investigated in the last 50 years for applications as bone substituting material and, more recently, for bone tissue engineering (Chen et al., 2006; Jones, 2013). Today, many different compositions of bioactive glasses have been produced and tested successfully in vitro and in vivo (Jones, 2013; Balasubramanian et al., 2016; Kankare and Lindfors, 2016; Baino et al., 2018; Westhauser et al., 2019).

The great interest in bioactive glasses relates to their surface reactivity leading to their ability to support the formation of new tissue and regenerate defects, which has been documented not only in bone but also in soft tissues (e.g. wound healing) (MiguezPacheco et al., 2015). When aqueous solutions get in contact with bioactive glasses, a series of reactions occur on the surface of the material. The exchange of ions with the surrounding medium promotes the dissolution of the BG and the formation of calcium phosphate (or hydroxyapatite) precipitates on the surface, which allows a strong bond of the implants or scaffolds to the surrounding bone tissue by the stimulation of bone cell differentiation and proliferation thereby inducing the formation of new bone tissue (Filgueiras et al., 1993; Brauer, 2015; Boccaccini et al., 2016). Angiogenic effects of BGs have also been reported (Gorustovich et al., 2010), both in vitro and in vivo, which has confirmed the great potential of the material for tissue engineering.

Zein belongs to the family of prolamine proteins, a type of corn protein, which makes up to $50 \%$ of the whole protein amount in corn (Shukla and Cheryan, 2001). Due to its outstanding filmforming ability as well as biodegradability and biocompatibility, zein is currently used in food production and food packing as well as in the pharmaceutical field, e.g. as edible coating agent for medication, food supplements or sweets (Corradini et al., 2014). The biocompatibility and biodegradability of zein make it very interesting also for the biomedical field (Demir et al., 2017). Possible biomedical applications of zein include its use in tissue engineering, for example as electrospun nanofiber mats, coating of metallic implants, as well as a carrier system for drug delivery or encapsulation of micronutrients (Paliwal and Palakurthi, 2014; Meyer et al., 2018; Pedram Rad et al., 2018; Vogt et al., 2018; Mariotti et al., 2020).

To integrate drug delivery carriers and bone tissue engineering scaffolds, polymer coatings are a commonly utilized approach (Yao et al., 2013; Li et al., 2014; Philippart et al., 2014). In this study, 45S5 BG scaffolds were produced via the standard polymer foam replication technique (Chen et al., 2006). Manuka honey was used as an antibacterial agent incorporated in a biopolymer coating based on corn protein zein in order to investigate, for the first time, the combined effects of $45 \mathrm{~S} 5 \mathrm{BG}$ and $\mathrm{MH}$ in a new scaffold type.

\section{MATERIALS AND METHODS}

\section{Scaffold Production}

Three-dimensional BG-based scaffolds were produced by means of the well-known foam replica technique (Chen et al., 2006). To prepare the slurry, melt-derived 45S5 BG powder with a particle size of $<4 \mu \mathrm{m}$ (Vitryxx ${ }^{\circledR}$ Schott, Mainz, Germany), polyvinyl alcohol (PVA, fully hydrolyzed, Mw 30000 Merck Millipore, Darmstadt, Germany) as a binder and deionized water were used. Initially PVA was dissolved in deionized water at $80^{\circ} \mathrm{C}$ in a ratio of $0.01 \mathrm{~mol} / \mathrm{L}$, followed by $1 \mathrm{~h}$ magnetic stirring. The solution was left to cool down to room temperature. $45 \mathrm{~S} 5$ BG powder was slowly added up to a concentration of $40 \mathrm{wt} . \%$ and the suspension was magnetically stirred for $1 \mathrm{~h}$. The chosen sacrificial template was polyurethane (PU) foam of 45 ppi (Eurofoam Deutschland $\mathrm{GmbH}$ ). The foams were initially cut with a cylindrical puncher and cleaned with acetone, afterwards they were coated twice by dipping them in the BG slurry and magnetically stirred for $1 \mathrm{~min}$, finally the excess slurry was manually squeezed out and the specimens were left to dry overnight in a drying furnace at $60^{\circ} \mathrm{C}$. Subsequently, the samples underwent a heat treatment 
in which the sacrificial template and organic components of the slurry were burned out and the sintering of the 45S5 BG structure occurred (Hum and Boccaccini, 2018). Initially the temperature was increased to $400^{\circ} \mathrm{C}$ and held for $1 \mathrm{~h}$ to burn out the PU foam. Afterwards, to complete the sintering process and the densification of the glass structure, the temperature was increased to $1050^{\circ} \mathrm{C}$ at $2^{\circ} \mathrm{C} / \mathrm{min}$ and held for $2 \mathrm{~h}$ followed by natural cooling down in the furnace.

\section{Coating with Biopolymer}

10 wt $\%$ zein (Sigma Aldrich, Munich, Germany) was slowly added into an 80 vol\% ethanol-solution under stirring conditions at room temperature for 30-60 min to allow the zein to dissolve, afterwards 10 and 20 wt.\% Manuka honey (TranzAlpineHoney ${ }^{\circledR}$ NZ) with a methylglyoxal (MGO) content of $>400 \mathrm{mg} / \mathrm{kg}$ was added and the solution was further magnetically stirred for at least $5 \mathrm{~h}$ until a homogeneous solution was obtained. The coating of the BG scaffold was performed by dipping each scaffold for $3 \mathrm{~min}$ in the zein-MH solution, followed by the removal of the excess of solution by gently rolling and tapping the samples over tissue paper and final drying at room temperature.

\section{Scaffold Characterization Scanning Electron Microscopy (SEM)}

A scanning electron microscope (Auriga, Carl-Zeiss, Jena, Germany) was used to evaluate the microstructure of the scaffolds and the quality of the coatings at an accelerating voltage of $1.5 \mathrm{kV}$ and a working distance of $\sim 6 \mathrm{~mm}$. Before SEM observation, samples were fixed with conductive silver paint and sputtered with gold (Quorum Q150T Turbo-Pumped Sputter Coater, Darmstadt, Germany).

\section{Light Microscopy}

The morphology of the scaffold, in particular the pore structure, was evaluated with a light microscope Stemi 508 (Carl Zeiss, Jena).

\section{Calculation of Porosity}

The porosity of the coated samples was calculated and compared to the porosity of the uncoated scaffolds. The porosity $(\mathrm{P})$ was calculated by the gravimetric method using the bulk and apparent densities, as shown in Eqs 1, 2 (Chen and Boccaccini, 2006):

$$
\begin{aligned}
& P=1-\frac{\rho_{\text {sample }}}{\rho_{\text {material }}} \\
& P=1-\left(\frac{\rho_{\text {uncoated Scaffold }}}{\rho_{B G}}+\frac{\rho_{\text {coated Scaffold }}}{\rho_{\text {coating material }}}\right)
\end{aligned}
$$

where $\rho_{\text {sample }}$ is the apparent density of the specimen calculated by dividing the weight by the volume of the scaffold and $\rho_{\text {material }}$ is the theoretical density of the struts, being $\rho_{B G}$ the density of $45 \mathrm{~S} 5 \mathrm{BG}$ and $\rho_{\text {coating material }}$ the density of zein and $\mathrm{MH}$. For the samples coated with only zein, the density was calculated taking into account the weight of the scaffolds before and after coating. Similarly, the density of the samples coated with zein and $\mathrm{MH}$ was obtained considering the weight of samples only coated with zein and samples coated with both zein and $\mathrm{MH}$.
The values of theoretical density for 45S5 BG, zein and $\mathrm{MH}$ were $2.7 \mathrm{~g} / \mathrm{cm}^{3}$ (Chen and Boccaccini, 2006), $1.22 \mathrm{~g} / \mathrm{cm}^{3}$ (Gong et al., 2006), and $1.4 \mathrm{~g} / \mathrm{cm}^{3}$ (Cooper et al., 2002), respectively.

\section{Mechanical Properties}

The compressive strength of cylindrical scaffolds of $8 \mathrm{~mm}$ height and $7 \mathrm{~mm}$ diameter (nominal dimensions) was evaluated by uniaxial compression strength tests using an electromechanical universal testing machine (Instron 3300 Floor Model, Instron ${ }^{\circledR}$ $\mathrm{GmbH}$, Germany). Five replicas of each sample were compressed at a speed of $1 \mathrm{~mm} / \mathrm{min}$ and a maximum applied force of $100 \mathrm{~N}$.

\section{Evaluation of Bioactivity}

The in vitro acellular bioactivity of the scaffolds was evaluated by immersion in simulated body fluid (SBF) using the well-known protocol of Kokubo et al. (Kokubo and Takadama, 2006). Samples were placed in scratch-free polypropylene containers, with $50 \mathrm{ml}$ of SBF in an orbital shaker at $90 \mathrm{rpm}$ and $37^{\circ} \mathrm{C}$. After different time points samples were removed, washed with ultrapure water and left to dry at room temperature. The formation of hydroxycarbonate apatite on the surface of the scaffolds was evaluated with SEM and Fourier transform infrared spectroscopy (FTIR), (IRAffinity-1S, Shimadzu Europa $\mathrm{GmbH})$.

\section{Manuka Honey Release Behavior}

The concentration of $\mathrm{MH}$ released from the scaffolds was measured with a UV-Vis spectrophotometer (Specord ${ }^{\circledR} 40$, Analytic Jena, Germany). The measurements were carried out at the characteristic absorbance peak of $\mathrm{MH}$ at $268 \mathrm{~nm}$. Initially, a calibration curve with different concentrations of MH in phosphate-buffered saline (PBS) was obtained (1.25, $2.5,5,7.5,10 \mathrm{mg} / \mathrm{ml}, 15 \mathrm{mg} / \mathrm{ml}$ and $20 \mathrm{mg} / \mathrm{ml}$ ). Scaffolds were immersed in $2 \mathrm{ml}$ of PBS and placed in an orbital shaker at $90 \mathrm{rpm}$ and $37^{\circ} \mathrm{C}, 1 \mathrm{ml}$ the solution was measured after different time points. The measurements were carried out in triplicate.

\section{Antibacterial Activity}

The antibacterial activity of the scaffolds was evaluated against Gram-positive bacteria $S$. aureus. The scaffolds were sterilized with UV light irradiation for $2 \mathrm{~h}$. Bacteria colonies were incubated in $10 \mathrm{ml}$ of Luria/Miller medium (LB medium; Carl Roth, Germany) for $24 \mathrm{~h}$ at $37^{\circ} \mathrm{C} \cdot 10^{6}-10^{7}$ bacteria in $2 \mathrm{ml}$ medium were added in each well-plate and incubated with the scaffolds for up to $8 \mathrm{~h}$ at $120 \mathrm{rpm}$ and $37^{\circ} \mathrm{C}$. To evaluate the metabolic activity of bacteria, Alamar blue (Invitrogen, United States) was added after $8 \mathrm{~h}$ and incubated according to the manufacture's protocol, subsequently absorbance measurements at 570 and $600 \mathrm{~nm}$ were performed and the reduction of Alamar blue was calculated. Additionally, the viability of incubated bacteria in contact with the samples was assessed at different time points using solid agar plates (LB Agar; Carl Roth, Germany). After each incubation time, $100 \mu \mathrm{l}$ of supernatant was plated onto the agar plate and the growth of bacteria was observed after $24 \mathrm{~h}$ incubation at $37^{\circ} \mathrm{C}$. Turbidity measurements were carried out measuring the optical density at $600 \mathrm{~nm}$ using a photometer (Thermo Scientific 


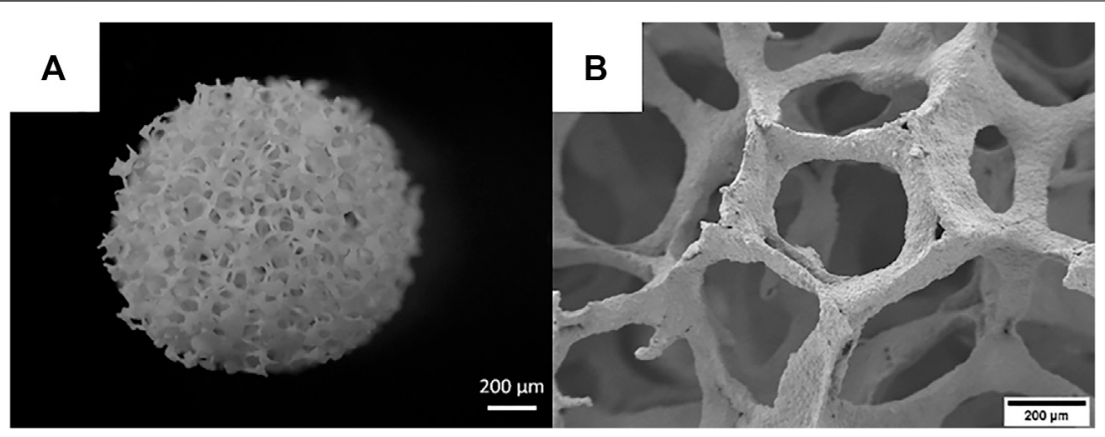

FIGURE 1 | Optical microscope (A) and SEM (B) images of sintered 45S5 BG scaffolds.

GENESYS 30, Germany). Samples of bacteria without scaffolds were used as control. The experiments were carried out in triplicate.

\section{RESULTS}

\section{Production of Scaffolds and Coating}

The microstructure of the scaffolds was studied by both SEM and optical microscopy. Highly porous BG scaffolds were obtained. Figures 1A,B shows the typical interconnected porous structure of the scaffolds at two magnifications, showing a structure similar to cancellous bone, typical of scaffolds obtained by the replica method (Chen et al., 2006).

Figure 2 depicts different coatings on BG scaffolds. Initially, a coating consisting only of zein was obtained, as can be observed in Figures 2A,B, the coating covered well the surface of the scaffold, and only a few pores were seen to be blocked with zein. Additional cracks and nanopores were also observed. When $\mathrm{MH}$ is incorporated into the coating solution, it can be detected in the scaffold as the black or dark gray spots and lines shown in the SEM pictures (Figures 2C-F). Two concentrations of $\mathrm{MH}$ were tested by incorporating $10 \mathrm{wt} \%$ and $20 \mathrm{wt} \% \mathrm{MH}$ into the zein coating solutions. Even though the coating solution with $\mathrm{MH}$ was thicker compared to the zein solution, in terms of coating quality and blockage of pores, no significant difference was observed with increasing amount of $\mathrm{MH}$.

The FTIR spectra of BG powder (sintered following the same procedure used for making the scaffolds), zein and $\mathrm{MH}$ are depicted in Figure 3. The absorbance spectra show peaks according to the vibrational bands of the materials. Sintered 45S5 BG shows prominent broad peaks in the regions $1150-960 \mathrm{~cm}^{-1}$ as well as $960-850 \mathrm{~cm}^{-1}$, which can be assigned to the vibrational bands of $\mathrm{Si}-\mathrm{O}-\mathrm{Si}$ asymmetric stretching vibration. Furthermore, a prominent peak at around $445 \mathrm{~cm}^{-1}$ can be attributed to the rocking $\mathrm{Si}-\mathrm{O}-\mathrm{Si}$ vibration (Aguiar et al., 2009). Smaller peaks at 730 and $696 \mathrm{~cm}^{-1}$ can be identified as symmetric stretching vibration of a Si-O-Si crystalline phase, indicating that the scaffold partly crystallizes during the sintering process, which is well-known from previous work (Chen et al., 2006). Peaks at around 620 and $524 \mathrm{~cm}^{-1}$ indicate the presence of crystalline phosphate since they can be assigned to bending vibrations of a crystalline phosphate phase (Filho et al., 1996), whereas the peak at $575 \mathrm{~cm}^{-1}$ can be identified as a vibrational band of amorphous P-O bending (Filho et al., 1996; Lefebvre et al., 2007; Chen et al., 2010; Adams et al., 2013). The FTIR spectrum of zein (Figure 3B) shows the characteristic vibrational bands for proteins, including a broad peak at $3290 \mathrm{~cm}^{-1}$ with a shoulder at about $3320 \mathrm{~cm}^{-1}$. This peak can be identified as the Amide A peak and is assigned to $\mathrm{O}-\mathrm{H}$ and $\mathrm{N}-\mathrm{H}$ stretching vibrations of amino acids. The spectrum also exhibits peaks at 3060 and $2930 \mathrm{~cm}^{-1}$ due to aromatic and aliphatic $\mathrm{C}-\mathrm{H}$ stretching, respectively. The prominent peak at $1645 \mathrm{~cm}^{-1}$ represents the Amide I peak and can be attributed primarily to $\mathrm{C}=\mathrm{O}$ (carbonyl) stretching vibrations (Forato et al., 1998). The Amide II peak at $1523 \mathrm{~cm}^{-1}$ contributes to $\mathrm{N}-\mathrm{H}$ bending of the peptide backbone of the protein. Another small peak at $1238 \mathrm{~cm}^{-1}$ can be assigned to axial deformation of C-N bonds (Magoshi et al., 1992; Forato et al., 1998; Corradini et al., 2014). The spectrum of MH (Figure 3C) shows the characteristic peaks for carbohydrates since it mainly consists of hydrated glucose and fructose as well as some smaller amounts of more complex carbohydrates like saccharides. The peak at $3260 \mathrm{~cm}^{-1}$ corresponds to $\mathrm{O}-\mathrm{H}$ stretching (H-bonded), the peak at $2930 \mathrm{~cm}^{-1}$ can be assigned to stretching of $\mathrm{C}-\mathrm{H}$ groups (Corradini et al., 2014). Both peaks can also be seen in the zein spectrum. Furthermore, a peak at $1645 \mathrm{~cm}^{-1}$ can be attributed to $\mathrm{O}-\mathrm{H}$ water bending. More peaks between 1,500 and $700 \mathrm{~cm}^{-1}$ correspond to characteristic vibration bands of carbohydrates (Svečnjak et al., 2011; Arslan et al., 2014; Head et al., 2015; Sabri and See, 2016).

FTIR spectra of the coated scaffolds were analyzed to confirm the presence of $\mathrm{MH}$ in the coating. In Figure 3D The spectrum of zein coated BG scaffold shows characteristic zein peaks at 3290 , 2930, 1645, and $1523 \mathrm{~cm}^{-1}$. Because zein and MH exhibit some common vibrational bands, the peaks overlap and cannot be specifically assigned. Nevertheless, the presence of $\mathrm{MH}$ in the coating can be identified in the larger and wider peak at $3260 \mathrm{~cm}^{-1}$ (O-H stretching), compared to the zein coated BG scaffold. Additionally, an increased peak at wavenumber $1026 \mathrm{~cm}^{-1}$ in the coated scaffold is attributed to $\mathrm{MH}$, this absorption band is characteristic of carbohydrates (Svečnjak et al., 2011). 


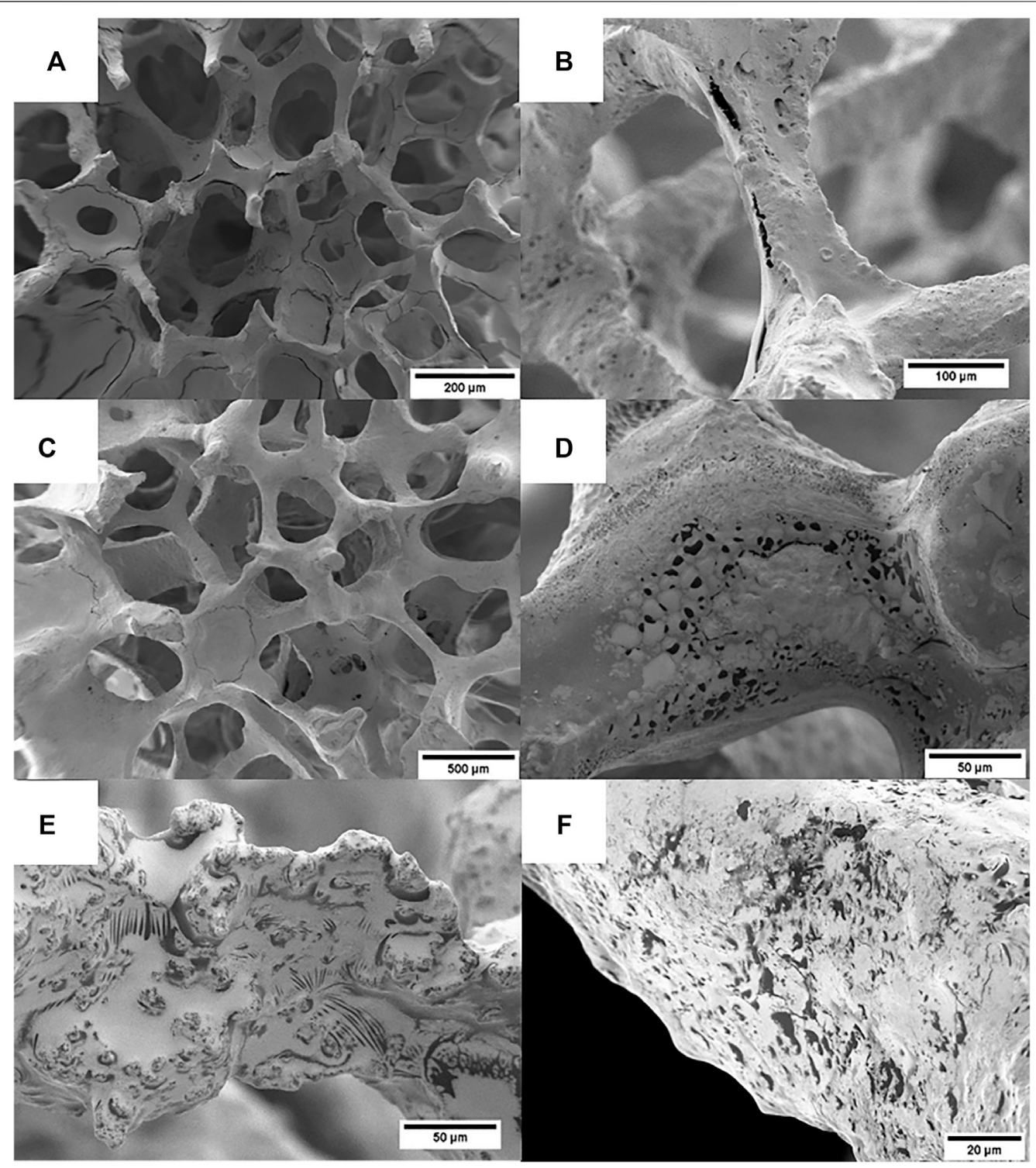

FIGURE 2 |SEM images of coated scaffolds: (A,B) zein coated scaffolds, (C-E) zein +10 wt.\% MH scaffolds, (F) zein +20 wt. \% MH scaffolds. MH can be identified in the coating as the black/dark areas.

\section{Porosity}

High porosity is particularly important for BTE applications since pores are needed not only for vascularization of the scaffold but also for cell attachment, differentiation and proliferation (Karageorgiou and Kaplan, 2005). Osteoblasts need to be able to penetrate the scaffold's porosity and to attach on its surface. High porosity is also crucial for a suitable degradation of the scaffold, since a higher porosity results in a higher surface in contact with body fluids. Although scaffolds with lower porosities have successfully been used for bone tissue engineering, for highly porous scaffolds like the ones prepared by the foam replica method the desired porosity is over $90 \%$, which is beneficial for bone regeneration (Chen et al., 2006). This very high porosity, on the other hand, leads to very low compression strength of the scaffolds (Philippart et al., 2014).

As can be seen in Table 1, uncoated BG scaffolds developed in this study showed a very high porosity of $95.6 \%$. This porosity lays in a suitable range for bone tissue engineering scaffolds (Bose et al., 2012). The zein coating decreases the porosity of the scaffold in around 5\%. The addition of $10 \mathrm{wt} . \% \mathrm{MH}$ to the coating led to a decrease of porosity of around $8 \%$ when compared to the zein coated scaffolds. Similarly, for the 20 wt.\% MH scaffolds the decrease of porosity was $~ 5 \%$. This reduction could be a consequence of the higher viscosity of the coating solution. The high content of $\mathrm{MH}$ makes the consistency of the coating gluier, making more difficult for the excessive 

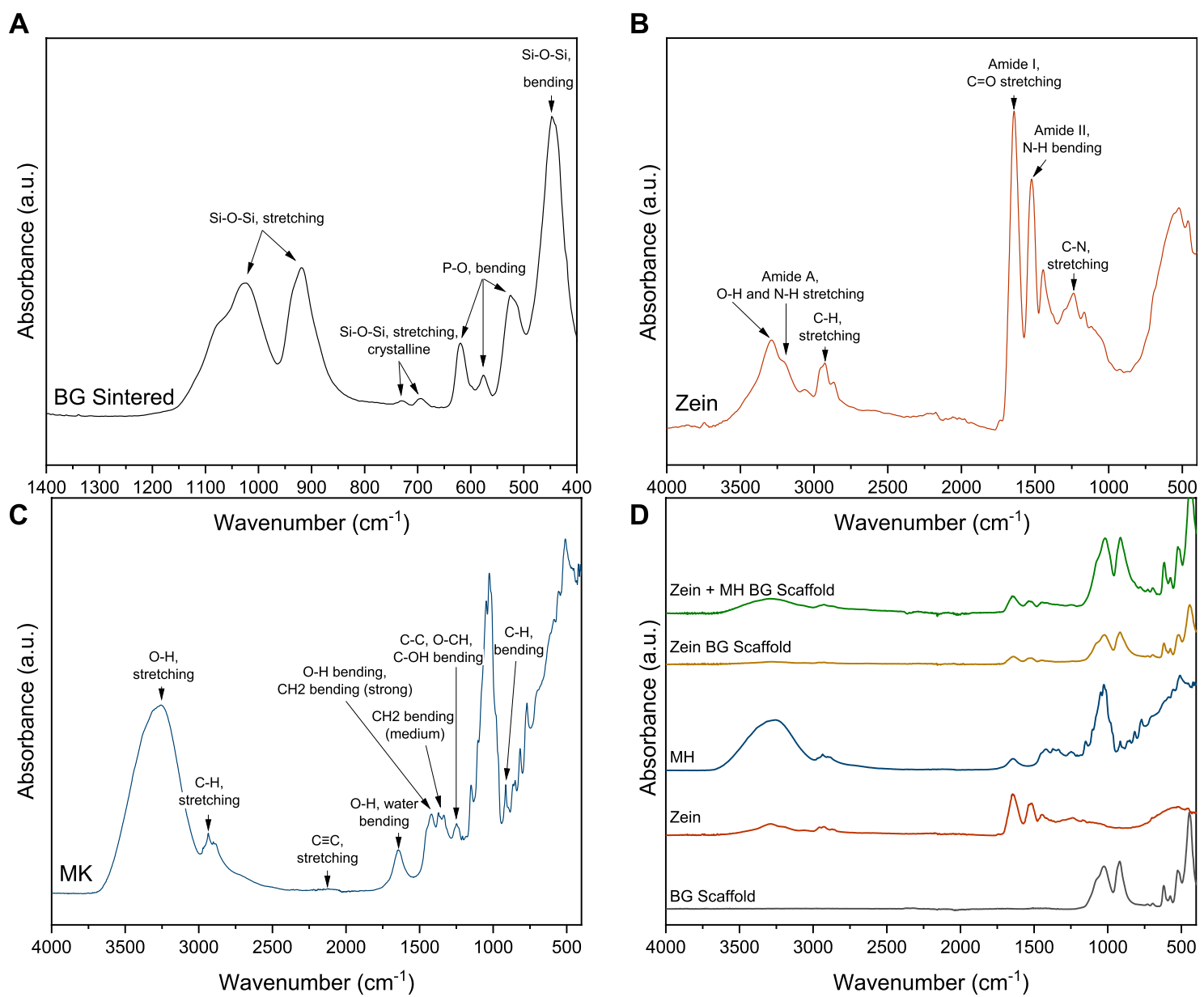

FIGURE 3 FTIR spectra with characteristic vibrational bands of (A) sintered 45S5 BG powder, (B) zein, (C) MH and (D) coated scaffolds. (The relevant peaks are discussed in the text).

TABLE 1 | Porosity of uncoated and coated BG scaffolds.

\begin{tabular}{lcc}
\hline Type of coating & Average porosity [\%] & Standard deviation \\
\hline Uncoated BG & 95.6 & 0.3 \\
Zein & 90 & 1 \\
Zein $+10 w t \%$ MH & 82 & 2 \\
Zein +20 wt $\%$ MH & 77 & 3
\end{tabular}

coating solution to flow out of the scaffold, even with the help of compressed air.

\section{Mechanical properties}

Compressive strength tests were carried out to evaluate the potential use of the coated scaffolds in bone tissue engineering applications in terms of their robustness and structural integrity under loads. Figure 4 shows representative stress-strain curves for uncoated and coated BG scaffolds which can be divided into three different areas. In stage I, the overall stress increases up to a maximum value at which the thick and strong struts of the

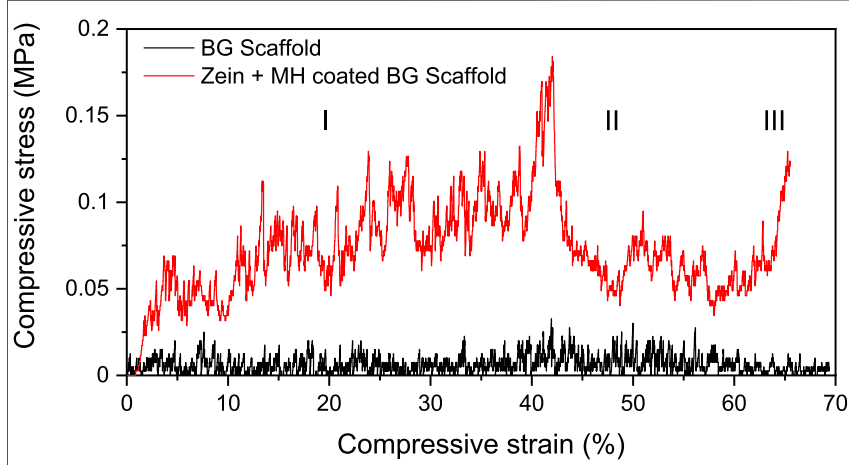

FIGURE 4 | Representative stress-strain curves for coated and uncoated BG scaffolds.

scaffold start to break. This leads to a decrease in compressive stress in area II. Eventually, in stage III, the stress rises again as the crushed scaffold gets compacted (Chen et al., 2006). The coating 
with zein and $\mathrm{MH}$ leads to an increase of the compressive strength of the scaffold in comparison to the uncoated one. Both curves are typical stress-strain curves for the compression of porous bioactive glass based structures (Philippart et al., 2014; Hum and Boccaccini, 2018). The jagged course of the curves originates from the porous structure and cracked surface of the thin struts. When the stress rises, struts start to break, leading to a temporary decrease of stress resulting in a characteristic jagged curve and a low compressive strength of $0.04 \pm 0.01 \mathrm{MPa}$, value which is comparable to results reported in the literature for similar scaffold types (Li et al., 2015; Hum and Boccaccini, 2018). For the coated scaffold with $\mathrm{MH}$ and zein, the average maximum compressive strength notably increased to $0.14 \pm 0.05 \mathrm{MPa}$. In the present investigation, the maximum compressive strength was estimated as the maximum stress applied before the densification of the scaffold took place, a concept that has been employed previously (Chen et al., 2006; Hum and Boccaccini, 2018).

The enhanced compressive strength of the coated scaffolds might be associated with the well-known reinforcement effect of the polymer infiltration into the cracks and open hollow struts of BG scaffolds (Philippart et al., 2014). Additionally, the properties of zein and MH can provide mechanical stability since zein has an extraordinary film-forming ability and can, therefore, form a smooth coating on the struts of the BG scaffold, closing microcracks and strengthening the brittle structure. As a possible disadvantage, when zein dries it can be hard and brittle. Consequently, plasticizers are used as an alternative to overcome the problem (Zhang et al., 2015). MH could act as a plasticizer for zein. Sugars like glucose and fructose, which make up the major component of honey, have been shown to reduce the stiffness and brittleness of zein films (Ghanbarzadeh et al., 2006; Ghanbarzadeh et al., 2007). Similarly, phenolic compounds in honey could act as plasticizers, as studies have shown (Arcan and Yemenicioglu, 2011), demonstrating that phenolic acids, gallic acid, p-hydroxybenzoic acid and ferulic acid, which are also present in $\mathrm{MH}$, can improve the flexibility of zein films. Indeed, the work of fracture of the coated scaffolds is notably higher than that of the uncoated scaffolds, as can be inferred in a first qualitative approximation by the extension of the area under the stress-strain curve.

However, when comparing the present results to the compressive strength of human cancellous bone, there is still room for improvement. The mechanical strength of the coated BG scaffolds is located only at the lower limit of the compressive strength of cancellous bone which ranges from $0.1-16 \mathrm{MPa}$ (Gerhardt and Boccaccini, 2010).

\section{Evaluation of bioactivity}

The formation of hydroxycarbonate apatite (HCA) on the surface of the scaffolds was investigated through SEM observations and FTIR analysis after immersion of the samples in SBF for different incubation times. Figure 5 depicts the surface changes of the coated scaffolds. After one day incubation, the coating already starts to degrade and flakes off in some areas of the scaffold, whereas some patches of coating remain on struts. Additionally, no dark dots of $\mathrm{MH}$ can be seen in the coating after one day of immersion. After three days in SBF, the coating is degraded further and eventually, the growth of apatite like structures on the surface increases significantly after seven days of immersion. Part of the coating is still visible and partially covered by calcium phosphate precipitates, which are qualitatively recognized by the cauliflower-like shape, as observed in Figure 5 (14 d SBF). As has been reported in the literature (Metze et al., 2013; Hum and Boccaccini, 2018), uncoated 45S5 BG scaffolds show the formation of apatite like structures already after just 1-day of immersion in SBF. Therefore the bioactive behavior of the scaffolds is slightly delayed by the zein coating.

HCA formation was confirmed using FTIR spectroscopy (Figure 6). After one day in SBF, the characteristic $\mathrm{MH}$ peak at $3620 \mathrm{~cm}^{-1}$ was not detected, therefore, wavenumbers in the range $2000-500 \mathrm{~cm}^{-1}$ are chosen for comparison since all important vibrational bands and peak changes are present in this range. After 7 days incubation, a peak at $575 \mathrm{~cm}^{-1}$ assigned to amorphous $\mathrm{P}-\mathrm{O}$ bending is slightly shifted and increases at a wavenumber of $560 \mathrm{~cm}^{-1}$, indicating the formation of an amorphous calcium phosphate layer. Together with a peak growing at $600 \mathrm{~cm}^{-1}$ it forms a double peak assigned to the bending vibrations of phosphate groups. This double peak typically indicates the formation of hydroxyapatite since it is characteristic for an orthophosphate lattice. Another peak forms between 1130 and $975 \mathrm{~cm}^{-1}$ with a shoulder at $960 \mathrm{~cm}^{-1}$ indicating the formation of a phosphate enriched crystalline hydroxyapatite layer attributed to the stretching of $\mathrm{PO}_{4}$ groups (Koutsopoulos, 2002; Stanciu et al., 2007; Macon et al., 2015; Hum, 2016).

Furthermore, a peak at wavenumber of $800 \mathrm{~cm}^{-1}$ can be assigned to the typical silica-rich layer on the scaffold surface (Cerruti et al., 2005). The $\mathrm{pH}$ of the SBF solution was measured after each incubation time. Figure 6B shows the fast increase of $\mathrm{pH}$ during the first days of immersion. After one week the $\mathrm{pH}$ has risen to nearly 7.7 and then it stays relatively stable at this value for the last two weeks of the test. This significant increase in $\mathrm{pH}$ is typical for bioactive glasses as the dissolving glass rapidly releases ions like sodium and calcium in exchange of protons from the surrounding SBF (Ciraldo et al., 2018). The higher ion concentration causes the increase in $\mathrm{pH}$ and favors the dissolution of the $\mathrm{Si}-\mathrm{O}-\mathrm{Si}$ bonds followed by the formation of HCA on the surface of the scaffold. Studies have shown that a higher alkaline $\mathrm{pH}$ (7.5 and 8.0) is an ideal environment for the formation of HCA (De Aza et al., 1996).

\section{Release behavior of $\mathrm{MH}$}

The concentrations of $\mathrm{MH}$ released from the scaffolds in PBS were measured with a UV-Vis spectrometer after different time points. The measured values showed a surprisingly fast release of $\mathrm{MH}$ within the first hour of immersion in PBS. This result correlates with the SEM observations and FTIR spectra of the samples after immersion in SBF since after one day no $\mathrm{MH}$ was detected. As can be observed in Figure 7, after $1 \mathrm{~h}, \mathrm{MH}$ concentration stays relatively constant, indicating that no significant further release was taking place. The concentration of $\mathrm{MH}$ in the PBS solution with a volume of $2 \mathrm{ml}$ for each scaffold was about $5 \mathrm{mg} / \mathrm{ml}$ for the $10 \mathrm{wt} . \%$ and $7 \mathrm{mg} / \mathrm{ml}$ for the $20 \mathrm{wt} . \% \mathrm{MH}$ coating. These values, 


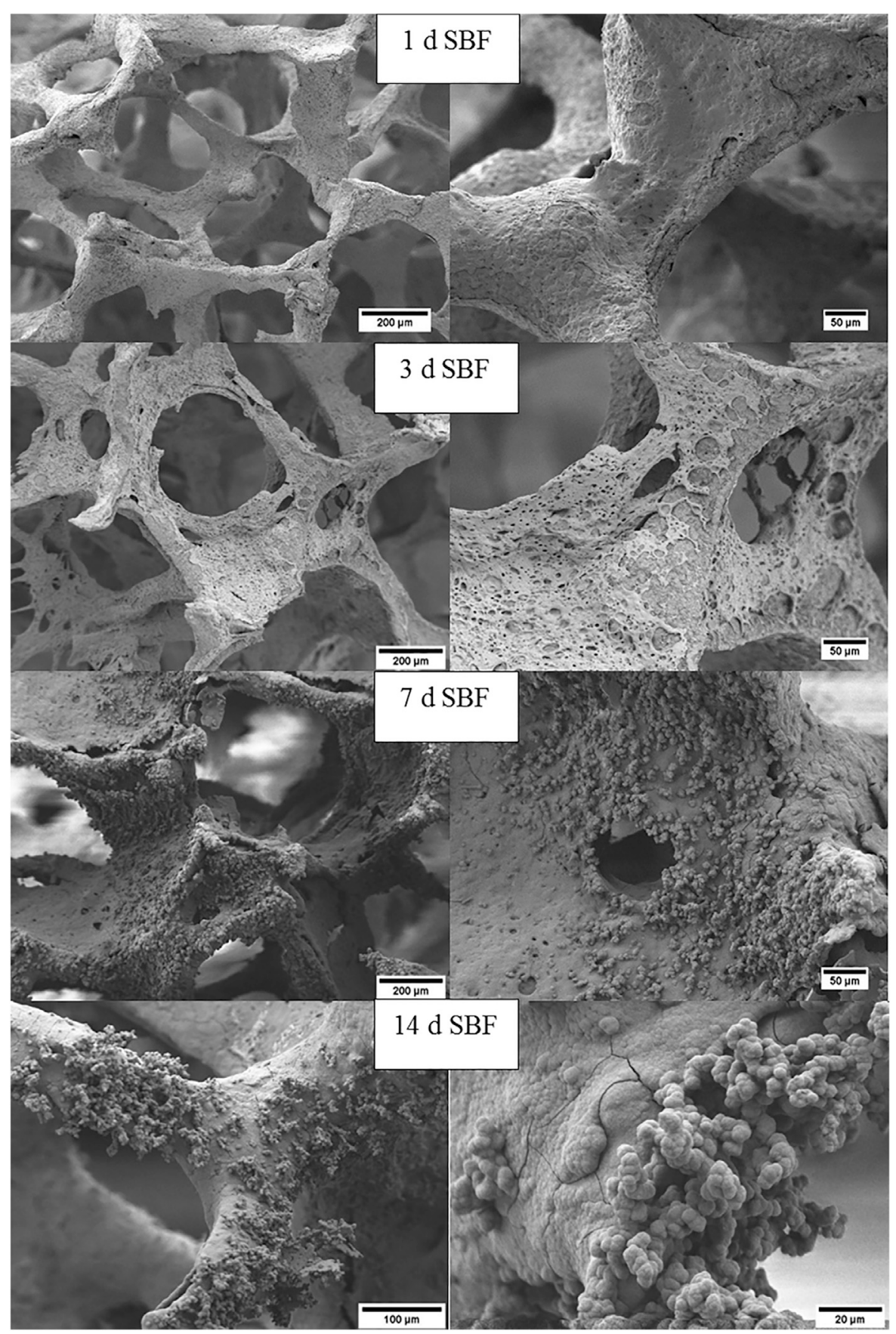

FIGURE 5 | SEM images at different magnifications of zein+MH coated BG scaffolds after immersion in SBF for 1, 3, 7, and 14 days.

however, are not very accurate as a great difference of $\mathrm{MH}$ concentration in PBS between the measured scaffolds can be seen.

Originally it was anticipated that zein would encapsulate $\mathrm{MH}$ and it was expected that a slow release of $\mathrm{MH}$ would occur, as it is the case for other types of drugs encapsulated in zein, like for instance oleic acid (Arcan and Yemenicioğlu, 2014). The fast release of $\mathrm{MH}$ is probably due to its good solubility in water and low encapsulation and distribution in the zein coating, therefore when water penetrates through pores in the zein coating $\mathrm{MH}$ is rapidly released.

\section{Antibacterial Properties}

The antibacterial activity of uncoated and coated scaffolds was assessed with $S$. aureus bacteria. The strongest antibacterial effect was observed for the coated scaffolds containing $\mathrm{MH}$. The coating with 20 wt.\% MH and zein showed significantly lower colony- 

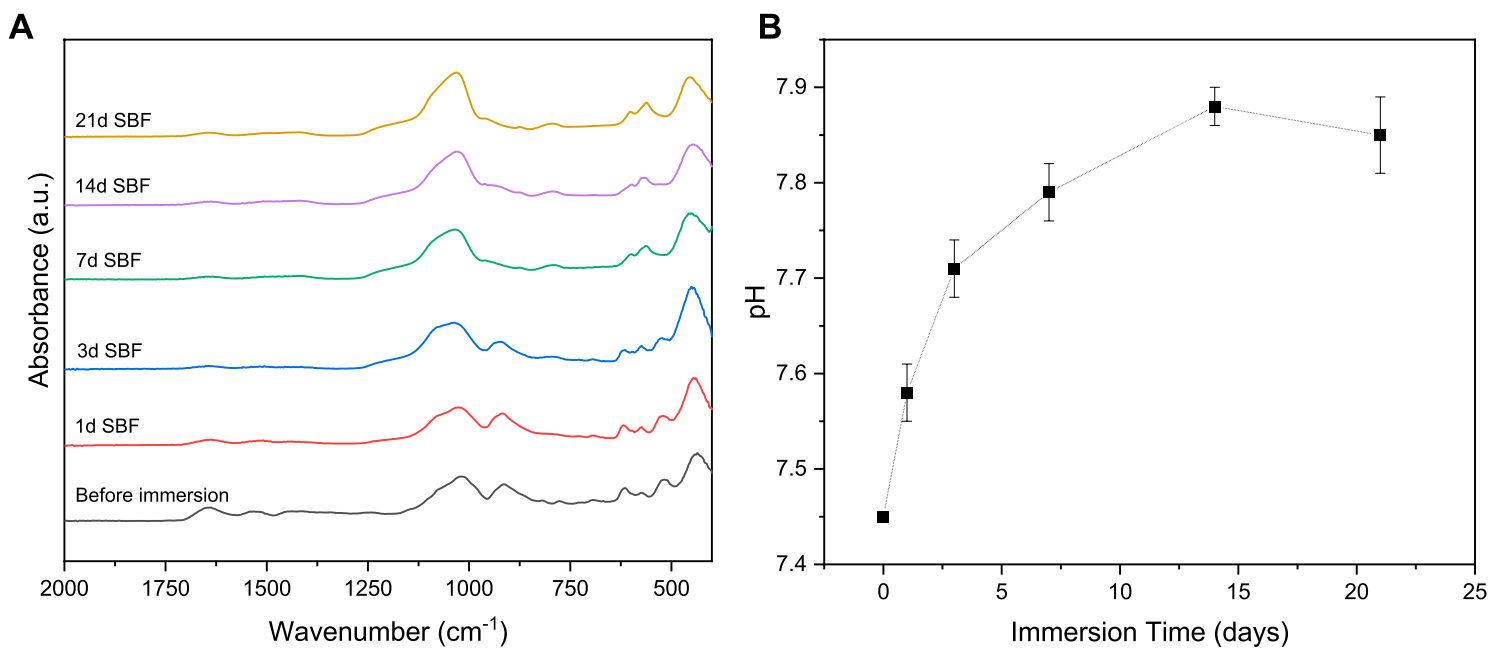

FIGURE 6 | (A) FTIR spectra of zein + MH coated BG scaffolds before and after immersion in SBF, (B) pH values of SBF after immersion of zein +MH coated BG scaffolds.

forming units of bacteria compared to the other samples, as depicted in Figure 8B. Similarly, after $2 \mathrm{~h}$ incubation, the values of the optical density (turbidity measurements) were lower for MH containing scaffolds, followed by zein coated and uncoated BG scaffolds, as shown in Figure 8A. Furthermore, the viability of bacteria was assessed via the reduction of Alamar blue, in accordance with the results of optical density at $8 \mathrm{~h}$, samples containing $\mathrm{MH}$ showed lower bacteria viability compared to the uncoated scaffolds and control sample with only $S$. aureus. Despite the fast release of $\mathrm{MH}$, it was possible to obtain an antibacterial effect of the coatings.

Representative pictures of the bacteria colony units in agar plates are shown in Figure 9. These plates correspond to $10^{-5}$ dilution for all tested samples. Therefore it is possible to directly compare the effect of each material on the bacterial growth. Significant differences can be observed between the $\mathrm{MH}$ containing scaffolds in which fewer or no bacteria colonies were counted compared to the control and the other samples. In the case of uncoated BG scaffolds, it was not possible to count the colonies since there was a joint of colonies instead of the individual ones observed in the other plates.

\section{DISCUSSION}

The combination of the biocompatibility and biodegradability of zein with the bioactive properties of BGs and the antibacterial effect of $\mathrm{MH}$ was shown to be an interesting approach to create multifunctional bone tissue engineering scaffolds. On the one hand, the zein coating containing $\mathrm{MH}$ covered the surface of the scaffolds without blocking pores or showing major cracks and irregularities. Moreover, $\mathrm{MH}$ was clearly recognized in the zein coating using scanning electron microscopy and FTIR spectroscopy. The coating successfully improved the mechanical properties of the porous and brittle

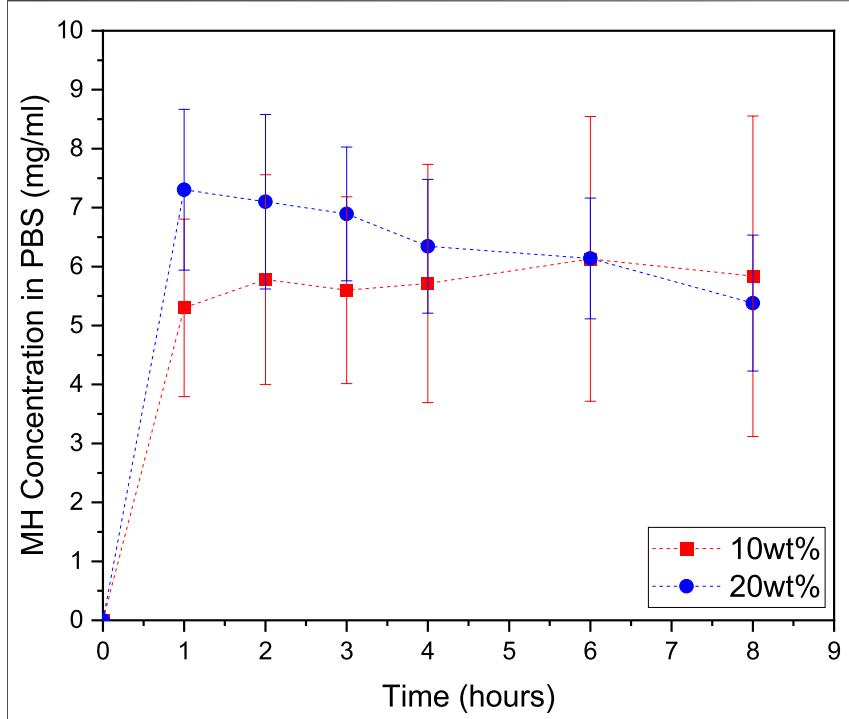

FIGURE 7 | Concentration of $\mathrm{MH}$ in solution after incubation of the coated scaffolds in PBS at $37^{\circ} \mathrm{C}$.

bioactive glass scaffolds. Even if the improvement is still not enough to make the coated scaffolds useful for load-bearing applications, especially the handling of the scaffolds was notably facilitated by the coating and coated scaffolds were much tougher (less prompt to brittle fracture) than their uncoated counterparts.

Additionally, the bioactive behavior of the scaffolds was not inhibited by the coating, as the zein - $\mathrm{MH}$ coating starts to degrade relatively fast after immersion in SBF and hydroxycarbonate apatite begins to grow on the strut surfaces after 3 days of immersion, which should favor a fast bonding to the surrounding bone. $\mathrm{MH}$ was successfully 

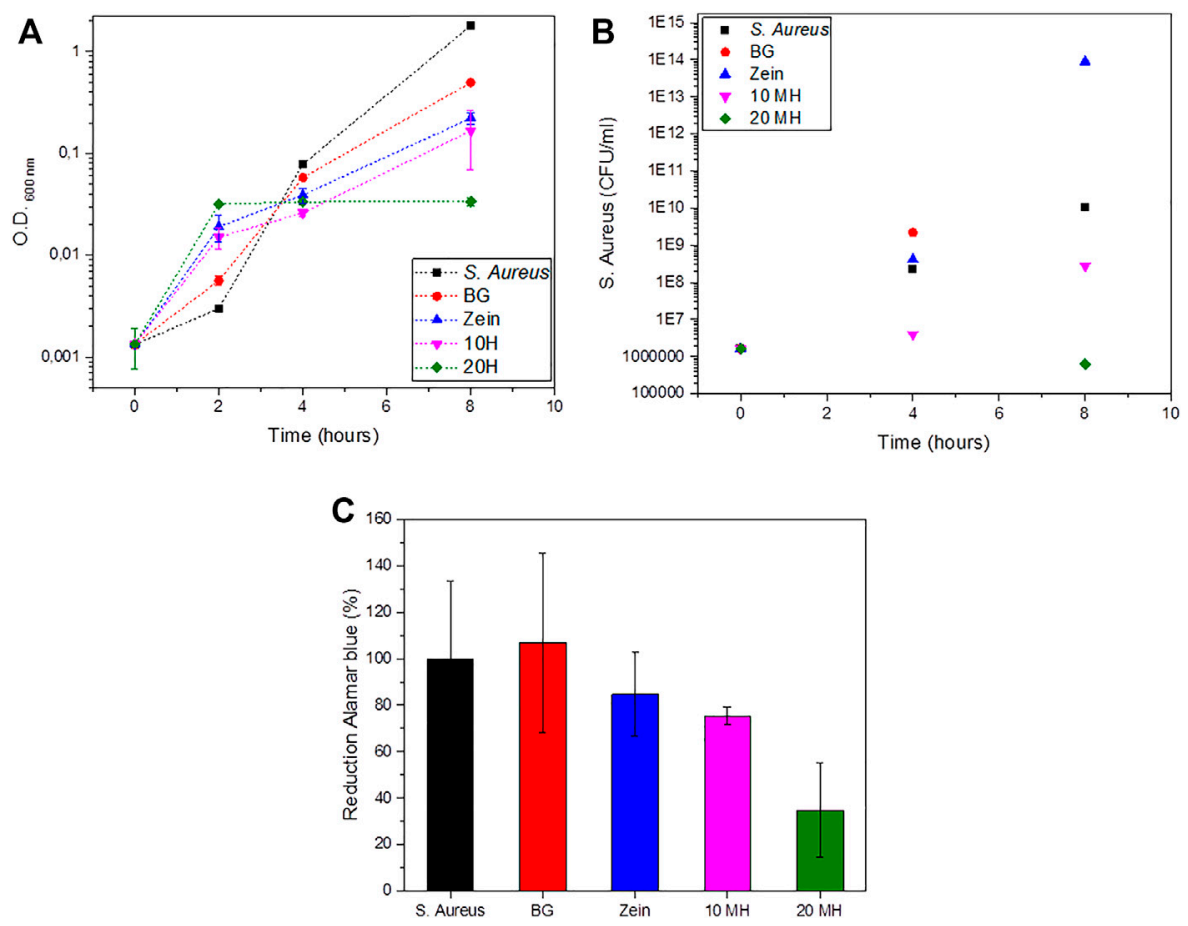

FIGURE 8 | Antibacterial behavior of uncoated and coated BG scaffolds. (A) Turbidity measurements. (B) Colony-forming units of S. aureus. (C) Reduction of Alamar blue after $8 \mathrm{~h}$.

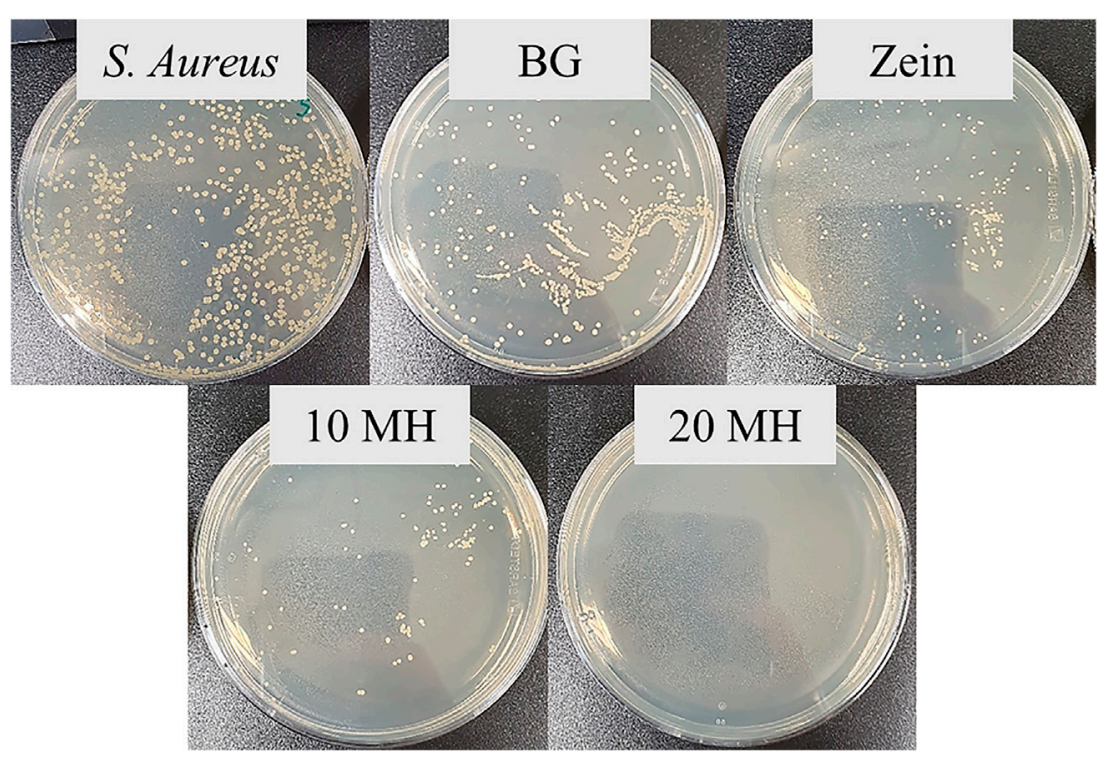

FIGURE 9 | Agar plates after $8 \mathrm{~h}$ incubation of S. aureus with supernatants of the $10^{-5}$ dilution of each sample.

released from the zein-coated scaffolds. However, some improvements are required, as the release of $\mathrm{MH}$ was considerably fast, likely due to MH's good solubility in aqueous environments and poor solubility in the solution of zein in ethanol. Therefore, it is likely that in the present technology, $\mathrm{MH}$ was not sufficiently embedded in the zein coating, which led to a rapid $\mathrm{MH}$ release in less than $1 \mathrm{~h}$. Consequently, no long-term antibacterial effect or activity 
against the formation of a biofilm on the scaffold can be expected, as $\mathrm{MH}$ diffuses quickly into the aqueous environment. Nevertheless, a superior antibacterial effect was observed for up to $8 \mathrm{~h}$ for the $\mathrm{MH}$ containing scaffolds. These results are in accordance with the recent literature, in which the antibacterial effect of $\mathrm{MH}$ in combination with BG particles and polymeric foams has been reported (Schuhladen et al., 2020). Further studies need to be carried out regarding the control of the release behavior of $\mathrm{MH}$. Alternative strategies to encapsulate $\mathrm{MH}$ need to be analyzed in order to obtain a sustained release and therefore to open the possibility of achieving long-term antibacterial effect.

\section{REFERENCES}

Adams, L. A., Essien, E. R., Shaibu, R. O., and Oki, A. (2013). Sol-Gel synthesis of $\mathrm{SiO} 2-\mathrm{CaO}-\mathrm{Na} 2 \mathrm{O}-\mathrm{P} 2 \mathrm{O} 5$ bioactive glass ceramic from sodium metasilicate. New J. Glass Ceram. 3, 11-15. doi:10.4236/njgc.2013.31003

Aguiar, H., Serra, J., González, P., and León, B. (2009). Structural study of sol-gel silicate glasses by IR and Raman spectroscopies. J. Non-Cryst. Solids 475-480. doi:10.1016/j.jnoncrysol.2009.01.010

Almasaudi, S. B., El-Shitany, N. A., Abbas, A. T., Abdel-Dayem, U. A., Ali, S. S., Al Jaouni, S. K., et al. (2016). Antioxidant, anti-inflammatory, and antiulcer potential of manuka honey against gastric ulcer in rats. Oxid. Med. Cell Longev. 2016, 3643824. doi:10.1155/2016/3643824

Alvarez-Suarez, J. M., Gasparrini, M., Forbes-Hernádez, T. Y., Mazzoni, L., and Giampieri, F. (2014). The composition and biological activity of honey focus on manuka honey. Foods 21, 420-432. doi:10.3390/foods3030420

Amini, A. R., Laurencin, C. T., and Nukavarapu, S. P. (2012). Bone tissue engineering: recent advances and challenges. Crit. Rev. Biomed. Eng. 40, 363-408. doi:10.1615/CritRevBiomedEng.v40.i5.10

Arcan, I., and Yemenicioglu, A. (2011). Incorporating phenolic compounds opens a new perspective to use zein films as flexible bioactive packaging materials. Food Res. Int. 44, 550-556. doi:10.1016/j.foodres.2010.11.034

Arcan, I., and Yemenicioğlu, A. (2014). Controlled release properties of zein-fatty acid blend films for multiple bioactive compounds. J. Agric. Food Chem. 62, 8238-8246. doi:10.1021/jf500666w

Arslan, A., Simsek, M., Aldemir, S. D., Kazaroglu, N. M., and Gumusderelioglu, M. (2014). Honey-based PET or PET/chitosan fibrous wound dressings: effect of honey on electrospinning process. J. Biomater. Sci. Polym. Ed. 25, 999-1012. doi:10.1080/09205063.2014.918455

Baino, F., Hamzehlou, S., and Kargozar, S. (2018). Bioactive glasses: where are we and where are we going? J. Funct. Biomater. 9, 25. doi:10.3390/jfb9010025

Balasubramanian, P., Grünewald, A., Detsch, R., Hupa, L., Jokic, B., Tallia, F., et al. (2016). Ion release, hydroxyapatite conversion, and cytotoxicity of boron-containing bioactive glass scaffolds. Int. J. Appl. Glass Sci. 7, 206-215. doi:10.1111/ijag.12206

Banerjee, D., and Bose, S. (2019). Effects of aloe vera gel extract in doped hydroxyapatitecoated titanium implants on in vivo and in vitro biological properties. ACS Appl. Bio. Mater 8, 3194-3202. doi:10.1021/acsabm.9b00077

Boccaccini, A. R., Brauer, D. S., and Hupa, L. Bioactive glasses: fundamentals, technology and applications. Cambridge: Royal Society of Chemistry. 2016. doi:10.1039/9781782622017

Bose, S., Roy, M., and Bandyopadhyay, A. (2012). Recent advances in bone tissue engineering scaffolds. Trends Biotechnol. 30, 546-554. doi:10.1016/j.tibtech.2012.07.005

Brauer, D. S. (2015). Bioactive glasses - structure and properties. Angew. Chem. Int. Ed. 54, 4160-4181. doi:10.1002/anie.201405310

Carter, D. A., Blair, S. E., Cokcetin, N. N., Bouzo, D., Brooks, P., Schothauer, R., et al. (2016). Therapeutic manuka honey: no longer so alternative. Front. Microbiol. 7, 569. doi:10.3389/fmicb.2016.00569

Cerruti, M., Greenspan, D., and Powers, K. (2005). Effect of $\mathrm{pH}$ and ionic strength on the reactivity of Bioglass ${ }^{\circledR}$ 45S5. Biomaterials 26, 1665-1674. doi:10.1016/j. biomaterials.2004.07.009

Chen, Q-Z., Li, Y., Jin, L-Y., Quinn, J. M. W., and Komesaroff, P. A. (2010). A new sol-gel process for producing $\mathrm{Na} 2 \mathrm{O}$-containing bioactive glass ceramics. Acta Biomater. 6, 4143-4153. doi:10.1016/j.actbio.2010.04.022

\section{DATA AVAILABILITY STATEMENT}

The raw data supporting the conclusions of this article will be made available by the authors, without undue reservation.

\section{AUTHOR CONTRIBUTIONS}

MA-O conceived the initial idea with AB; MA-O, JW, and KL planned and carried out the experiments; MA-O wrote the first draft of the paper; MA-O, KL, and JW contributed to the analysis of the data; $\mathrm{AB}$ supervised the project, provided intellectual input and corrected the manuscript.

Chen, Q. Z., and Boccaccini, A. R. (2006). Poly(D,L-lactic acid) coated $45 \mathrm{~S} 5$ Bioglass ${ }^{\circledR}$-based scaffolds: processing and characterization. J. Biomed. Mater. Res. 77, 445-457. doi:10.1002/jbm.a.30636

Chen, Q. Z., Thompson, I. D., and Boccaccini, A. R. (2006). 45S5 Bioglass ${ }^{\circledR}$-derived glass-ceramic scaffolds for bone tissue engineering. Biomaterials 27, 2414-2425. doi:10.1016/j.biomaterials.2005.11.025

Ciraldo, F. E., Boccardi, E., Melli, V., Westhauser, F., and Boccaccini, A. R. (2018). Tackling bioactive glass excessive in vitro bioreactivity: preconditioning approaches for cell culture tests. Acta Biomater. 75, 3-10. doi:10.1016/j.actbio.2018.05.019

Cloutier, M., Mantovani, D., and Rosei, F. (2015). Antibacterial coatings: challenges, perspectives, and opportunities. Trends Biotechnol. 33, 637-652. doi:10.1016/j.tibtech.2015.09.002

Cooper, R. A., Molan, P. C., and Harding, K. G. (2002). The sensitivity to honey of Gram-positive cocci of clinical significance isolated from wounds. J. Appl. Microbiol. 93, 857-863. doi:10.1046/j.1365-2672.2002.01761.x

Corradini, E., Curti, P. S., Meniqueti, A. B., Martins, A. F., Rubira, A. F., and Muniz, E. C. (2014). Recent advances in food-packing, pharmaceutical and biomedical applications of zein and zein-based materials. Int. J. Mol. Sci. 15, 22438-22470. doi:10.3390/ijms151222438

De Aza, P. N., Guitian, F., Merlos, A., Lora-Tamayo, E., and Aza, S. D. (1996). Bioceramics-simulated body fluid interfaces: $\mathrm{pH}$ and its influence of hydroxyapatite formation. J. Mater. Sci. Mater. Med. 7, 399-402.

Demir, M., Ramos-Rivera, L., Silva, R., Nazhat, S. N., and Boccaccini, A. R. (2017). Zein-based composites in biomedical applications. J. Biomed. Mater. Res. 7, 399-402. doi:10.1002/jbm.a.36040

Filgueiras, M. R., La Torre, G., and Hench, L. L. (1993). Solution effects on the surface reactions of a bioactive glass. J. Biomed. Mater. Res. 27, 445-453. doi:10. 1002/jbm. 820270405

Filho, O. P., LaTorre, G. P., and Hench, H. L. (1996). Effect of crystallization on apatite-layer formation of bioactive glass 45S5. J. Biomed. Mater. Res. 30, 509-514. doi:10.1002/(SICI)1097-4636(199604)30:4<509::AID-JBM9>3.0.CO;2-T

Forato, L. A., Bernardes-Filho, R., and Colnago, L. A. (1998). Protein structure in $\mathrm{KBr}$ pellets by infrared spectroscopy. Anal. Biochem. 259, 136-141.

Gerhardt, L-C., and Boccaccini, A. R. (2010). Bioactive glass and glass-ceramic scaffolds for bone tissue engineering. Materials (Basel) 3, 3867-3910. doi:10.3390/ma3073867

Ghanbarzadeh, B., Musavi, M., Oromiehie, A. R., Rezayi, K., Rad, E. R., and Milani, J. (2007). Effect of plasticizing sugars on water vapor permeability, surface energy and microstructure properties of zein films. LWT-Food Sci. Technol. 40, 1191-1197. doi:10.1016/j.lwt.2006.07.008

Ghanbarzadeh, B., Oromiehie, A. R., Musavi, M., D-Jomeh, Z. E., Rad, E. R., and Milani, J. (2006). Effect of plasticizing sugars on rheological and thermal properties of zein resins and mechanical properties of zein films. Food Res. Int. 39, 882-890. doi:10.1016/j.foodres.2006.05.011

Gong, S., Wang, H., Sun, Q., Xue, S. T., and Wang, J. Y. (2006). Mechanical properties and in vitro biocompatibility of porous zein scaffolds. Biomaterials 27, 3793-3799. doi:10.1016/j.biomaterials.2006.02.019

Gorustovich, A. A., Roether, J. A., and Boccaccini, A. R. (2010). Effect of bioactive glasses on angiogenesis: a review of in vitro and in vivo evidences. Tissue Eng. B Rev. 16, 199-207. doi:10.1089/ten.teb.2009.0416

Head, J., Kinyanjui, J., and Talbott, M. (2015). FTIR-ATR characterization of commercial honey samples and their adulteration with sugar syrups using chemometric analysis. Shimadzu Scientific Instruments, Columbia, MD, USA. Pittcon 2220-1. 
Hench, L. L., Splinter, R. J., Allen, W. C., and Greenlee, T. K. (1971). Bonding mechanisms at the interface of ceramic prosthetic materials. J. Biomed. Mater. Res. 5, 117-141. doi:10.1002/jbm.820050611

Hixon, K. R., Bogner, S. J., Ronning-Arnesen, G., Janowiak, B. E., and Sell, S. A. (2019). Investigating manuka honey antibacterial properties when incorporated into cryogel, hydrogel, and electrospun tissue engineering scaffolds. Gels 5, 21. doi:10.3390/gels5020021

Hum, J., and Boccaccini, A. R. (2018). Collagen as coating material for 45S5 bioactive glass-based scaffolds for bone tissue engineering. Int. J. Mol. Sci. 19, 1807. doi:10.3390/ijms19061807

Hum, J. K. Bioactive glass combined with natural derived proteins as composite materials for the application in bone tissue engineering Kompositmaterialien bestehend aus bioaktivem Glas und natürlichen Proteinen für die Anwendung im Knochen Tissue Engineering. 2016. 159.

Jones, J. R. (2013). Review of bioactive glass: from Hench to hybrids. Acta Biomater. 9, 4457-4486. doi:10.1016/j.actbio.2012.08.023

Kankare, J., and Lindfors, N. C. (2016). Reconstruction of vertebral bone defects using an expandable replacement device and bioactive glass S53P4 in the treatment of vertebral osteomyelitis: three patients and three pathogens. Scand. J. Surg. 105, 248-253. doi:10.1177/1457496915626834

Karageorgiou, V., and Kaplan, D. (2005). Porosity of 3D biomaterial scaffolds and osteogenesis. Biomaterials 26, 5474-5491. doi:10.1016/j.biomaterials.2005.02.002

Kokubo, T., and Takadama, H. (2006). How useful is SBF in predicting in vivo bone bioactivity? Biomaterials 27, 2907-2915. doi:10.1016/j.biomaterials.2006.01.017

Koutsopoulos, S. (2002). Synthesis and characterization of hydroxyapatite crystals: a review study on the analytical methods. J. Biomed. Mater. Res. 62, 600-612. doi:10.1002/jbm.10280

Lefebvre, L., Chevalier, J., Gremillard, L., Zenati, R., Thollet, G., Bernache-Assolant, D., et al. (2007). Structural transformations of bioactive glass 4555 with thermal treatments. Acta Mater. 55, 3305-3313. doi:10.1016/j.actamat.2007.01.029

Li, W., Nooeaid, P., Roether, J. A., Schubert, D. W., and Boccaccini, A. R. (2014). Preparation and characterization of vancomycin releasing PHBV coated 45S5 Bioglass ${ }^{\circledR}$-based glass-ceramic scaffolds for bone tissue engineering. J. Eur. Ceram. Soc. 34, 505-514. doi:10.1016/j.jeurceramsoc.2013.08.032

Li, W., Wang, H., Ding, Y., Scheithauer, E. C., Goudouri, O. M., Grünewald, A., et al. (2015). Antibacterial 45S5 Bioglass ${ }^{\circledR}$-based scaffolds reinforced with genipin cross-linked gelatin for bone tissue engineering. J. Mater. Chem. B 3, 3367-3378. doi:10.1039/c5tb00044k

Macon, A. L. B., Kim, T. B., Valliant, E. M., Goetschius, K., Brow, R. K., Day, D. E., et al. (2015). A unified in vitro evaluation for apatite-forming ability of bioactive glasses and their variants. J. Mater. Sci. Mater. Med. 26, 115. doi:10.1007/s10856-015-5403-9

Magoshi, J., Nakamura, S., and Murakami, K. (1992). Structure and physical properties of seed proteins. I. Glass transition and crystallization of zein protein from corn. J. Appl. Polym. Sci. 45, 2043-2048. doi:10.1002/app.1992.070451119

Mandal, M. D., and Mandal, S. (2011). Honey: its medicinal property and antibacterial activity. Asian Pac J. Trop. Biomed. 1, 154-160. doi:10.1016/ S2221-1691(11)60016-6

Mariotti, C. E., Ramos-Rivera, L., Conti, B., and Boccaccini, A. R. (2020). Zeinbased electrospun fibers containing bioactive glass with antibacterial capabilities. Macromol. Biosci. 20, 2000059. doi:10.1002/mabi.202000059

Mas-Moruno, C., Su, B., and Dalby, M. J. (2019). Multifunctional coatings and nanotopographies: toward cell instructive and antibacterial implants. $A d v$. Healthc. Mater. 8, e1801103. doi:10.1002/adhm.201801103

Metze, A. L., Grimm, A., Nooeaid, P., Roether, J. A., Hum, J., Newby, P. J., et al. (2013). Gelatin coated $45 \mathrm{~S} 5$ Bioglass $^{\circledR}$-derived scaffolds for bone tissue engineering. Key Eng. Mater. 541, 31-39. doi:10.4028/www.scientific.net/KEM.541.31

Meyer, N., Rivera, L. R., Ellis, T., Qi, J., Ryan, M. P., and Boccaccini, A. R. (2013). Bioactive and antibacterial coatings based on zein/bioactive glass composites by electrophoretic deposition. Coatings 8, 27. doi:10.3390/coatings8010027

Miguez-Pacheco, V., Hench, L. L., and Boccaccini, A. R. (2015). Bioactive glasses beyond bone and teeth: emerging applications in contact with soft tissues. Acta Biomater. 13, 1-15. doi:10.1016/j.actbio.2014.11.004

Minden-Birkenmaier, B. A., and Bowlin, G. L. (2018). Honey-based templates in wound healing and tissue engineering. Bioengineering 5, 46. doi:10.3390/ bioengineering5020046

Nooeaid, P., Li, W., Roether, J. A., Mouriño, V., Goudouri, O-M., Schubert, D. W., et al. (2014). Development of bioactive glass based scaffolds for controlled antibiotic release in bone tissue engineering via biodegradable polymer layered coating. Biointerphases 9, 041001. doi:10.1116/1.4897217

Paliwal, R., and Palakurthi, S. (2014). Zein in controlled drug delivery and tissue engineering. J. Control Release 189, 108-122. doi:10.1016/j.jconrel.2014.06.036

Pedram Rad, Z., Mokhtari, J., and Abbasi, M. (2018). Fabrication and characterization of $\mathrm{PCL} / z e i n / g u m$ Arabic electrospun nanocomposite scaffold for skin tissue engineering. Mater. Sci. Eng. C 93, 356-366. doi:10.1016/j.msec.2018.08.010

Philippart, A., Boccaccini, A. R., Fleck, C., Schubert, D. W., and Roether, J. A. (2014). Toughening and functionalization of bioactive ceramic and glass bone scaffolds by biopolymer coatings and infiltration: a review of the last 5 years. Expet Rev. Med. Dev. 12, 93-111. doi:10.1586/17434440.2015.958075

Porter, J. R., Ruckh, T. T., and Popat, K. C. (2009). Bone tissue engineering: a review in bone biomimetics and drug delivery strategies. Biotechnol. Prog. 25, 1539-1560. doi:10.1002/btpr.246

Sabri, N. F. M., and See, H. H. (2016). Classification of honey using fourier transform infrared spectroscopy and chemometrics. EProceedings Chem. 1.

Schuhladen, K., Mukoo, P., Liverani, L., Neščáková, Z., and Boccaccini, A. R. (2020). Manuka honey and bioactive glass impart methylcellulose foams antibacterial effects for wound healing applications. Biomed. Mater. 15, 065002. doi:10.1088/1748-605x/ab87e5

Schuhladen, K., Roether, J. A., and Boccaccini, A. R. (2019). Bioactive glasses meet phytotherapeutics: the potential of natural herbal medicines to extend the functionality of bioactive glasses. Biomaterials 217, 119288. doi:10.1016/j. biomaterials.2019.119288

Shukla, R., and Cheryan, M. (2001). Zein: the industrial protein from corn. Ind. Crop. Prod. 13, 171-192. doi:10.1016/S0926-6690(00)00064-9

Speer, S. L., Schreyack, G. E., and Bowlin, G. L. (2015). Manuka honey: a tissue engineering essential ingredient. J. Tissue Sci. Eng. 6, 1. doi:10.4172/2157-7552.1000e130

Stanciu, G. A., Sandulescu, I., Savu, B., Stanciu, S. G., Paraskevopoulos, K. M., Chatzistavrou, X., et al. (2007). Investigation of the hydroxyapatite growth on bioactive glass surface. J. Biomed. Pharm. Eng. 1, 34-39.

Svečnjak, L., Biliškov, N., Bubalo, D., and Barišić, D. (2011). Application of infrared spectroscopy in honey analysis. Agric. Conspectus Sci. 76, 191-195.

Thakur, R., Jain, N., Pathak, R., and Sandhu, S. S. (2011). Practices in wound healing studies of plants. Evidence-Based Complement Altern. Med. 2011, 438056. doi:10.1155/2011/438056

Vogt, L., Liverani, L., Roether, J. A., and Boccaccini, A. R. (2018). Electrospun zein fibers incorporating poly(glycerol sebacate) for soft tissue engineering. Nanomaterials 8, 150. doi:10.3390/nano8030150

Wang, J., Tian, L., He, L., Chen, N., Ramakrishna, S., So, K. F., et al. (2018). Lycium barbarum polysaccharide encapsulated Poly lactic-co-glycolic acid Nanofibers: cost effective herbal medicine for potential application in peripheral nerve tissue engineering. Sci. Rep. 8, 8669. doi:10.1038/s41598$018-26837-z$

Westhauser, F., Widholz, B., Nawaz, Q., Tsitlakidis, S., Hagmann, S., Moghaddam, A., et al. (2019). Favorable angiogenic properties of the borosilicate bioactive glass 0106-B1 result in enhanced in-vivo osteoid formation compared to $45 \mathrm{~S} 5$ Bioglass. Biomater. Sci. 7, 5161-5176. doi:10.1039/C9BM01220F

Yao, Q., Nooeaid, P., Roether, J. A., Dong, Y., Zhang, Q., and Boccaccini, A. R. (2013). Bioglass ${ }^{\circledR}$-based scaffolds incorporating polycaprolactone and chitosan coatings for controlled vancomycin delivery. Ceram. Int. 39, 7517-7522. doi:10. 1016/j.ceramint.2013.03.002

Zhang, Y., Cui, L., Che, X., Zhang, H., Shi, N., Li, C., et al. (2015). Zein - based films and their usage for controlled delivery: origin, classes and current landscape. J. Control Release 206, 206-219. doi:10.1016/j.jconrel.2015.03.030

Conflict of Interest: The authors declare that the research was conducted in the absence of any commercial or financial relationships that could be construed as a potential conflict of interest.

Copyright (C 2021 Arango-Ospina, Lasch, Weidinger and Boccaccini. This is an open-access article distributed under the terms of the Creative Commons Attribution License (CC BY). The use, distribution or reproduction in other forums is permitted, provided the original author(s) and the copyright owner(s) are credited and that the original publication in this journal is cited, in accordance with accepted academic practice. No use, distribution or reproduction is permitted which does not comply with these terms. 